\title{
Effects of Water-Cooled Loop Monopole Antenna on Microwave Ablation Efficiency
}

\author{
Adewumi Olumuyiwa FEMI 1 (D), Okechukwu Ebuka AGBASI ${ }^{2 *}$ (D), Fatile Oluwanifesii \\ EMMANUEL ${ }^{3}$ (D) Sunday Edet ETUK ${ }^{4}$ (i) \\ ${ }^{1}$ Department of Radiology, Federal Medical Center, Owo, Nigeria. \\ ${ }^{2 *}$ Department of Physics, Michael Okpara University of Agriculture, Umudike Nigeria. \\ ${ }^{3}$ Olusegun Obasanjo Presidential Library, Oke-Mosan, Abeokuta, Nigeria. \\ ${ }^{4}$ Departement of Physics, University of Uyo, Uyo, Nigeria.
}

\begin{abstract}
This work compares the effect of a monopole antenna without cooling unit on a biological tissue and a monopole antenna with cooling unit. Computer simulation was done using a computer software named COMSOL Multiphysics ${ }^{\mathrm{TM}}$, input power was varied from $10 \mathrm{~W}$ to $120 \mathrm{~W}$, with an interval of $10 \mathrm{~W}$, at different times, from 60 s to $120 \mathrm{~s}$ at an interval of $60 \mathrm{~s}$. It was observed that the diameter of the lowest power ( $20 \mathrm{~W})$ decreased by $-17.2 \%$ at $5 \mathrm{mins}$, the length decreased by $-32.9 \%$ and aspect ratio for the two antennas increased by $23.40 \%$. For medium power (60W), at 5 mins, the diameter decreased by $-9.89 \%$, length decreased by $-37.9 \%$, and aspect ratio decreased by $45.24 \%$. The $\mathrm{p}$-value obtained from diameter for low power showed no significant difference for ablation without water cool $(\mathrm{p}>$ $0.005)$, but showed significant difference with water cool $(\mathrm{p}<0.005)$, diameter for medium power showed no significant difference, $\mathrm{p}>0.005$ in both simulations, there was no statistically significant difference in the diameter for high power (110W and 120W) for both simulations, p-value $>0.005$. The result showed that inclusion of cooling unit reduced backward heating of microwave antenna, ablation length, and ablation diameter of simulated tissue.

Keywords: Aspect ratio, Closed loop, Microwave ablation, Significant difference.

${ }^{*}$ Corresponding author : Okechukwu Ebuka AGBASI e-mail : agbasi.okechukwu@gmail.com

Geliş tarihi / Received : 10.07.2019 Kabul tarihi / Accepted: 09.09.2019
\end{abstract}

\section{Introduction}

There is a wide spread of cancers today, hence, various treatment modalities such as the use of radiations (like $\mathrm{x}$-ray, gamma ray), ablation, ultrasound and others have been developed to approach different form of cancer cases. However, minimally invasive tissue ablation has become of central importance in the modern surgery armamentarium, because it does not involve the use of ionizing radiation which can be damaging to healthy tissues if not properly managed, it is also less invasive. In the treatment of benign or malignant tumors, it is important to achieve ablation of the undesirable tissue in a wellcontrolled and precise way without affecting the surrounding healthy tissue. As an alternative to surgical resection, numerous thermal and non- thermal ablation modalities are available, including: radiofrequency (RF) ablation, microwave ablation, cryoablation, high-intensity focused ultrasonography (US), laser ablation, irreversible electroporation, chemical ablation (with ethanol and acetic acid), and brachytherapy (Hinshaw et al., 2014; Simon, et al., 2005; Açıkgöz and Türer, 2014; Shock et al., 2004). These ablation therapies make use of different antennas: slot, dipole, cap-choke, sleeve and monopole (Kaur and Maini, 2007; Lin and Wang, 1996). However, monopole antennas are frequently use in tumor ablation (Bertram et al., 2006), this article focuses on effect of a closed loop monopole water cool antenna on microwave ablation efficiency. 


\section{Material and Methods}

\section{Material}

A computer software (COMSOL Multiphysics TM) was used for computer simulation. A $2.45 \mathrm{GHz}$ solid-state MW generator (SAIREM SAS 200W, NeyronCedex France), with a variable output power from 20 to $120 \mathrm{~W}$ in step of $10 \mathrm{~W}$ was used to generate power for different time durations. Monopole antenna was designed from a $50 \Omega$ UT0.085 ' semi rigid coaxial cable (RG405 Coax, Pasternack Enterprises Inc, Los Angeles, CA), the inner conductor was made from silver-plated copper clad steel, while the outer conductor was made of copper, and the coaxial dielectric used was a low-loss solid polytetrafluoroethylene (PTFE). The Polytetrafluoroethylene (PTFE) thread seal tape was used to enclose antennas to prevent adhesion of the probe to desiccated ablated tissue and to ensure easy removal of the antenna. A water-cooled syringe pump was used to pump cool water to the antenna, to cool the system and prevent backward heating. Channel Data logging Thermometer (SPER Scientific Ltd) was as well used to measure the temperature of the system. Micrometer screw gauge and ruler were used to measure the diameter of the antennas.

\section{Methods}

Computer simulation was done using a computer software named COMSOL Multiphysics ${ }^{\mathrm{TM}}$, input power was varied from $10 \mathrm{~W}$ to $120 \mathrm{~W}$, with an interval of $10 \mathrm{~W}$, at different times, from $60 \mathrm{~s}$ to 120 s at an interval of 60 s.

\section{Antenna Fabrication}

Monopole antenna were designed from $50 \Omega$ UT0.085 ' semi rigid coaxial cable (RG405 Coax, Pasternack Enterprises Inc, Los Angeles, CA). The antennas consist of thin coaxial cables with internal and external conductor made of copper, and their tip soldiered. The water-cooled antenna was enclosed in a sleeve (catheter) made of PTFE (polytetrafluoroethylene a biocompatible dielectric material) through which a cooling water could flow through. The antenna was operated at 2.45 $\mathrm{GHz}$, a frequency widely used in microwave coagulation therapy.

\section{Experimental Validation}

Experiments were performed with a customdesigned microwave applicator on ex-vivo bovine liver (cattle liver) obtained from a local abattoir. The applicator used for all experimentation was a 2.45 GHz, 200-Wmicrowave device with an active 5.7 -mm-diameter radiator, powered by a magnetron generator. The antenna was connected to the microwave generator (SAIREM SAS 200W, NeyronCedex France), and the generator output was set properly to ensure appropriate power delivery and to compensate for cable losses. ASP1800 syringe pump was used to pump water through the water-cooled antenna.

\section{Tissue Coagulation Process}

Input power and the slot size were set, other quantities such as reflection coefficient, total power dissipation, ablation diameter, ablation length and were determined. The parameters from the computer simulation were measured and recorded and the power generated by the simulation with the aid of a divider and a ruler. The ablated tissues were sliced along the antenna axis to determine the diameters and lengths of ablated zone. Each ablated zone was photographed for further analysis with ImageJ software. The aspect ratio was determined by dividing the measured tissue diameters by the tissue lengths.

\section{Statistical Analysis}

SPSS was used to analyze the data's, and paired $t$ test was used to obtain the p-values, standard deviation was used to show the variation and relation relationship between the obtained values. Also, the percentage differences in the ablation coagulation diameters, lengths and aspect ratios of the data were compared. 


\section{Results}

In the study, a total of 36 computer simulations were carried out and experimental validation was also done with bovine liver. Comparison the results of ablation with close looped monopole water cooled microwave antenna and result with monopole antenna that has no water cool system was made. The powers were 20, 30, 50, 60 and 110, 120 representing low, medium and high power respectively. The initial and final temperatures for every simulation was recorded. Thereafter, the diameter and length were measured to calculate the aspect ratio.
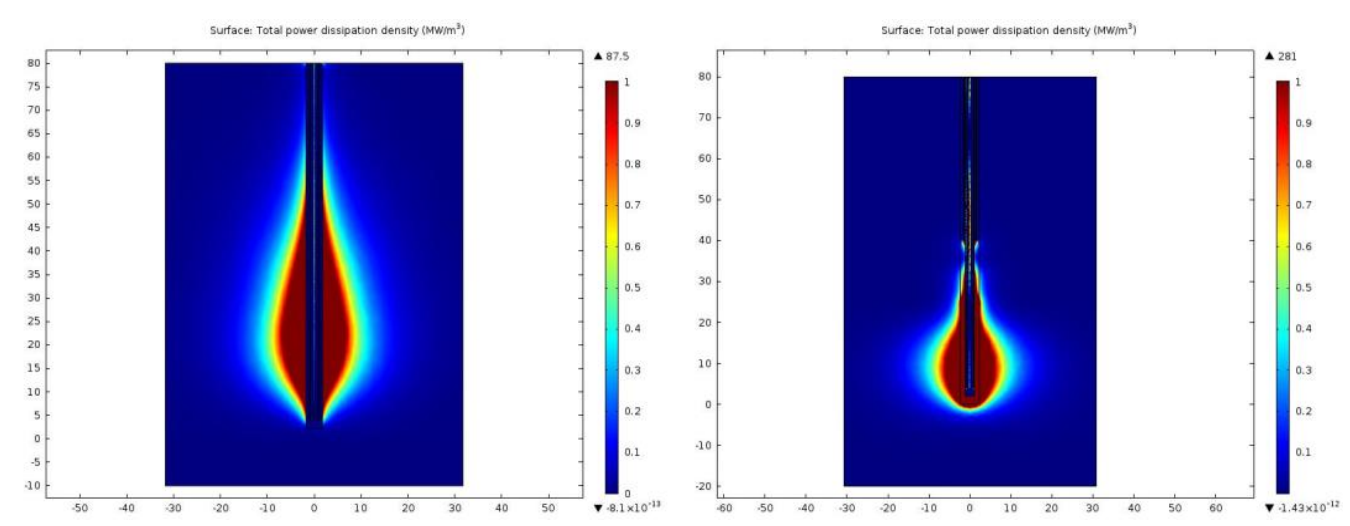

Figure 1a i and ii Result of 20W for 3min without water cool and with water cool respectively.
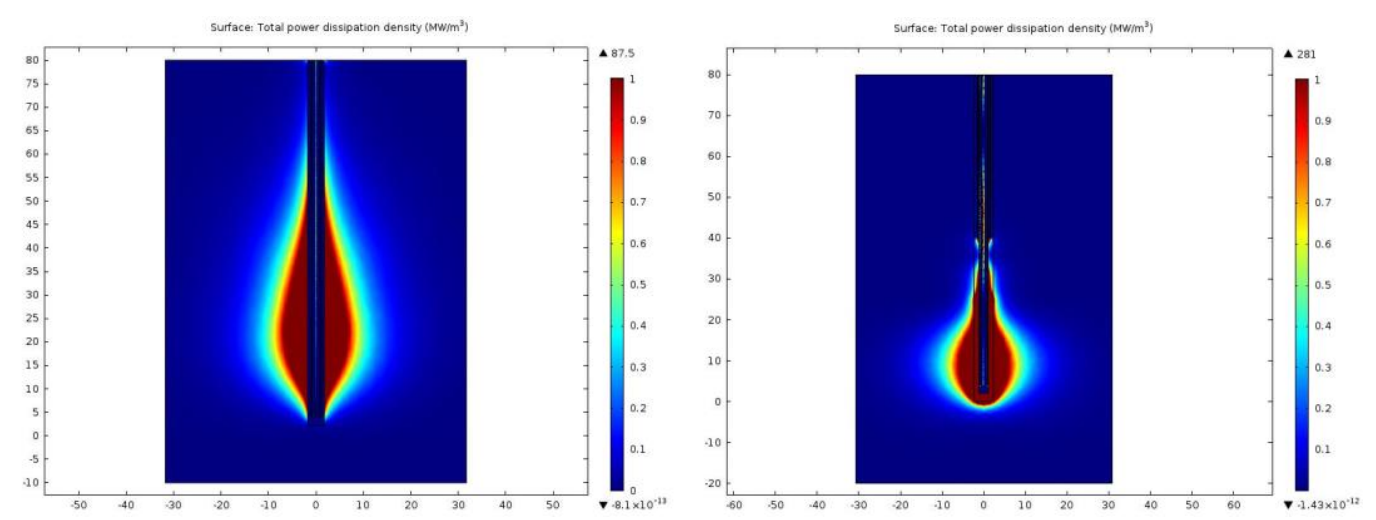

Figure $1 \mathbf{b}$ i and bii $20 \mathrm{~W}$ for $5 \mathrm{mins}$ without water cool and with water cool respectively. 

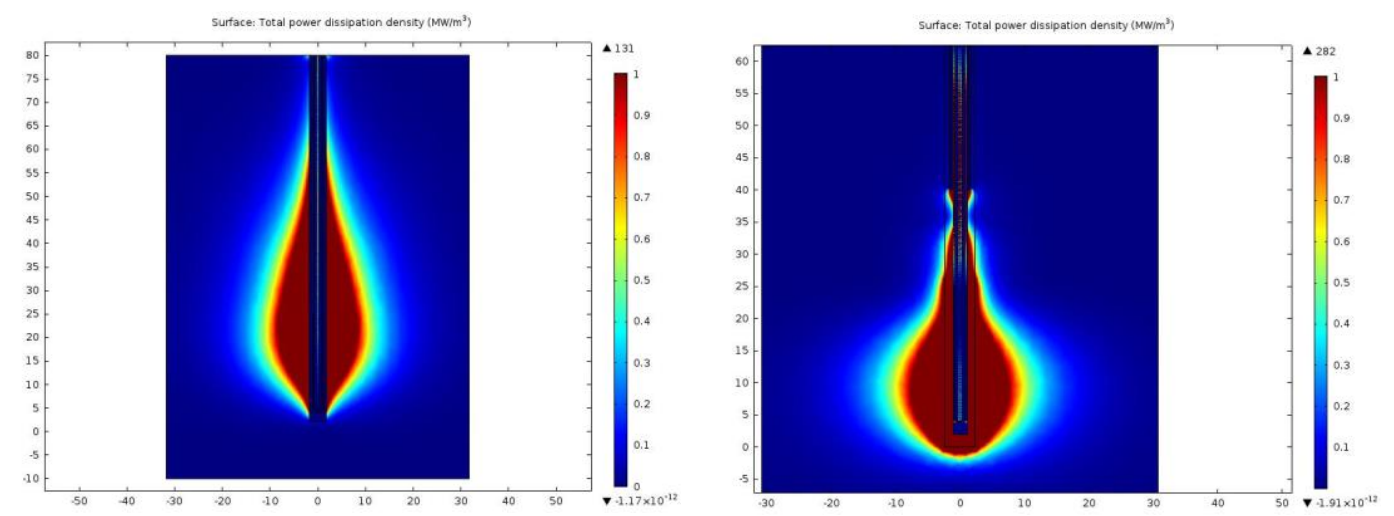

Figure 1c i and ii for 10min without water cool and with water cool respectively.
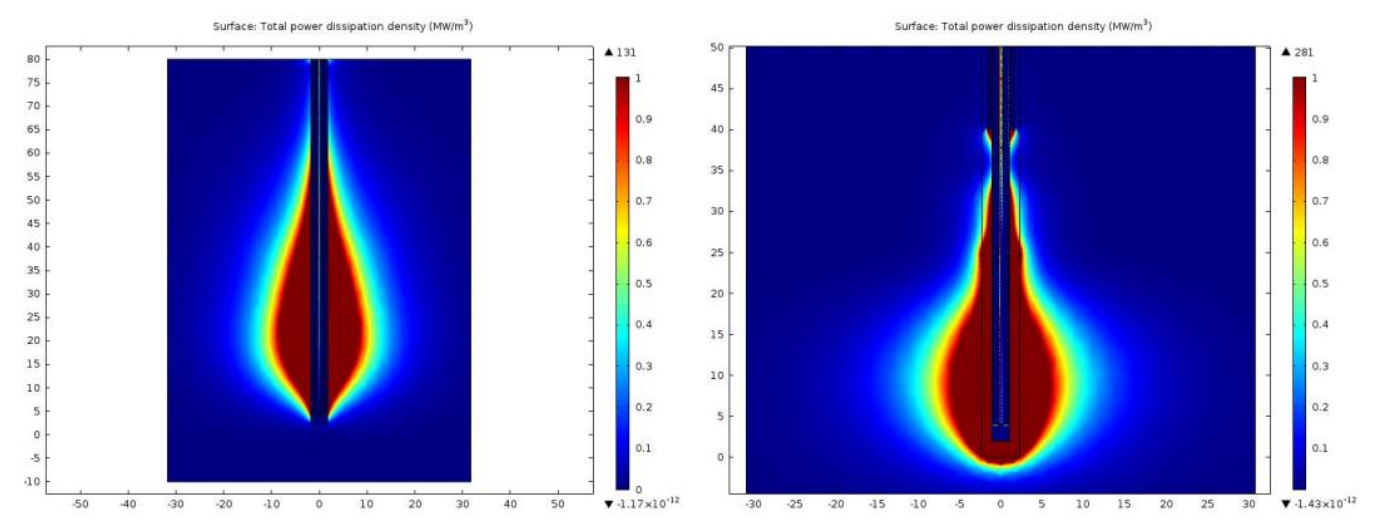

Figure 1d i and ii 30w for 3mins without water cool and with water cool respectively.
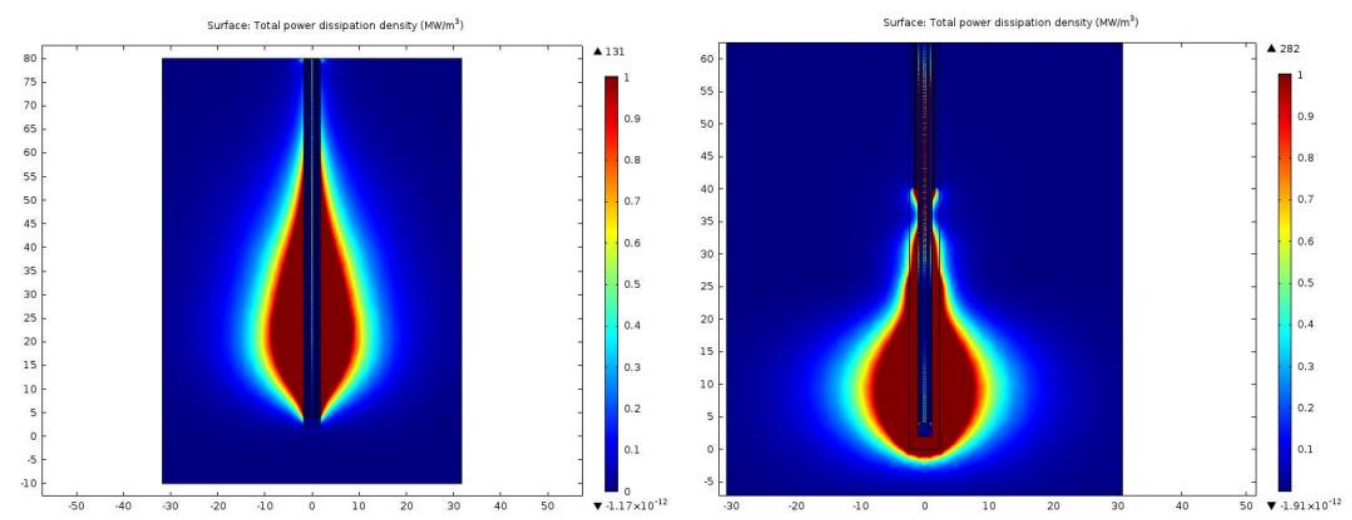

Figure 1 e i and ii 30w for 5 mins without water cool and with water cool respectively.

To cite this article: Femi AO, Agbasi OE, Emmanuel FO, Etuk SE. (2019). Effect of Water-Cooled Loop Monopole Antenna on Microwave Ablation Efficiency. MAKU J. Health Sci. Inst., 7(2), 41-54. 

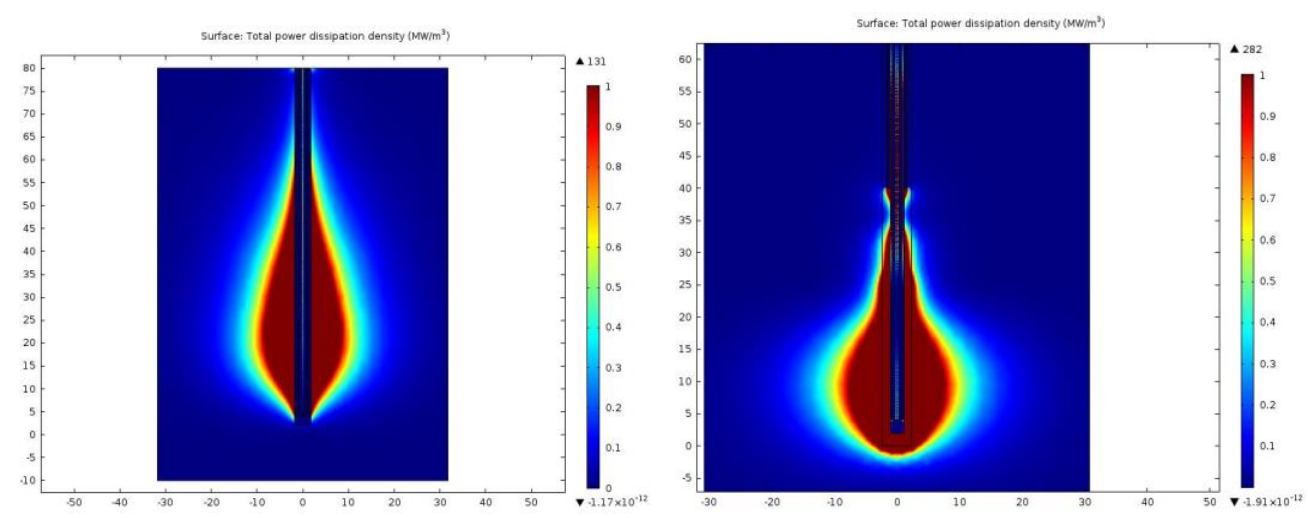

Figure $1 \mathbf{f} \mathbf{i}$ and ii 30 watts $10 \mathrm{mins}$ without water cool and with water cool respectively.
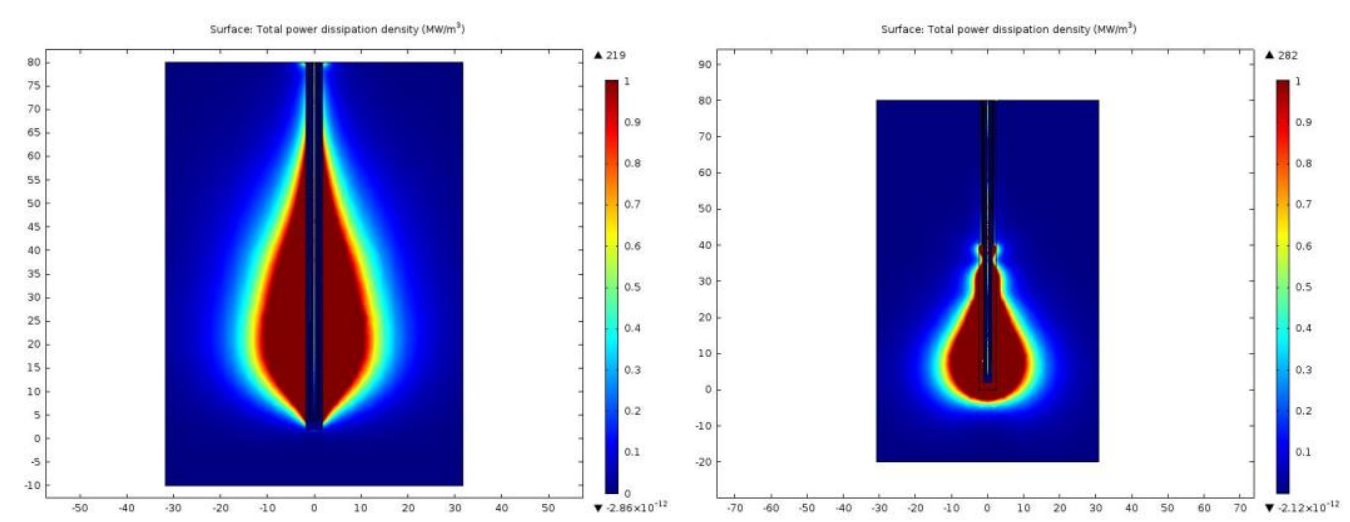

Figure $1 \mathrm{~g}$ i and ii 50w for 3mins, without water cool and with water cool respectively.
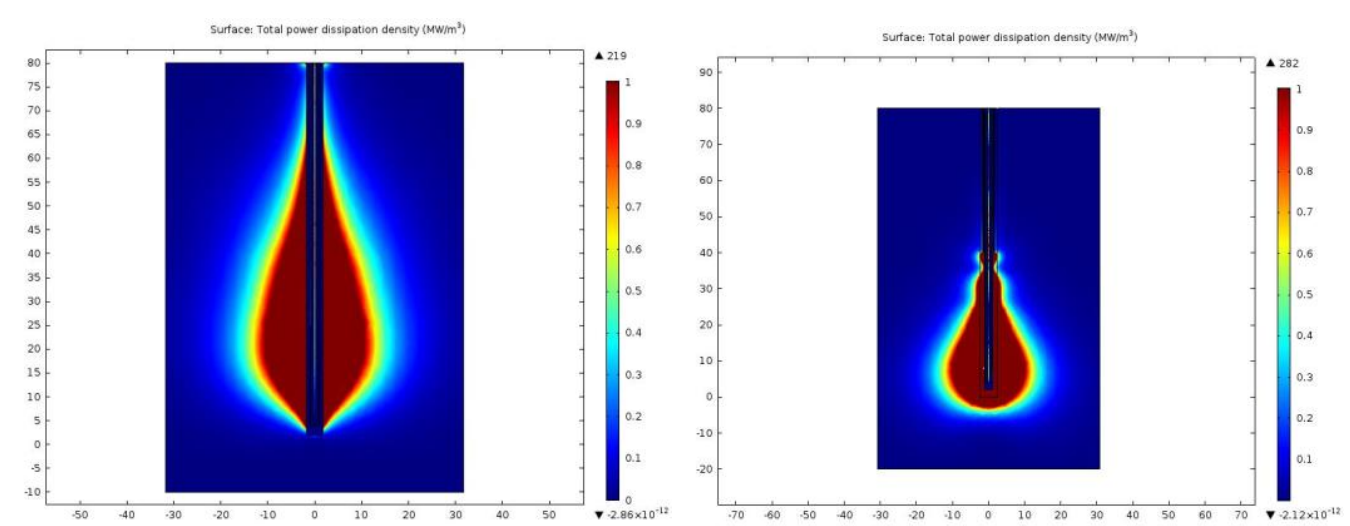

Figure $1 \mathrm{~h}$ iand ii $50 \mathrm{w}$ for $5 \mathrm{mins}$, without water cool and with water cool respectively.

To cite this article: Femi AO, Agbasi OE, Emmanuel FO, Etuk. SE. (2019). Effect of Water-Cooled Loop Monopole Antenna on Microwave Ablation Efficiency. MAKU J. Health Sci. Inst., 7(2), 41-54. 

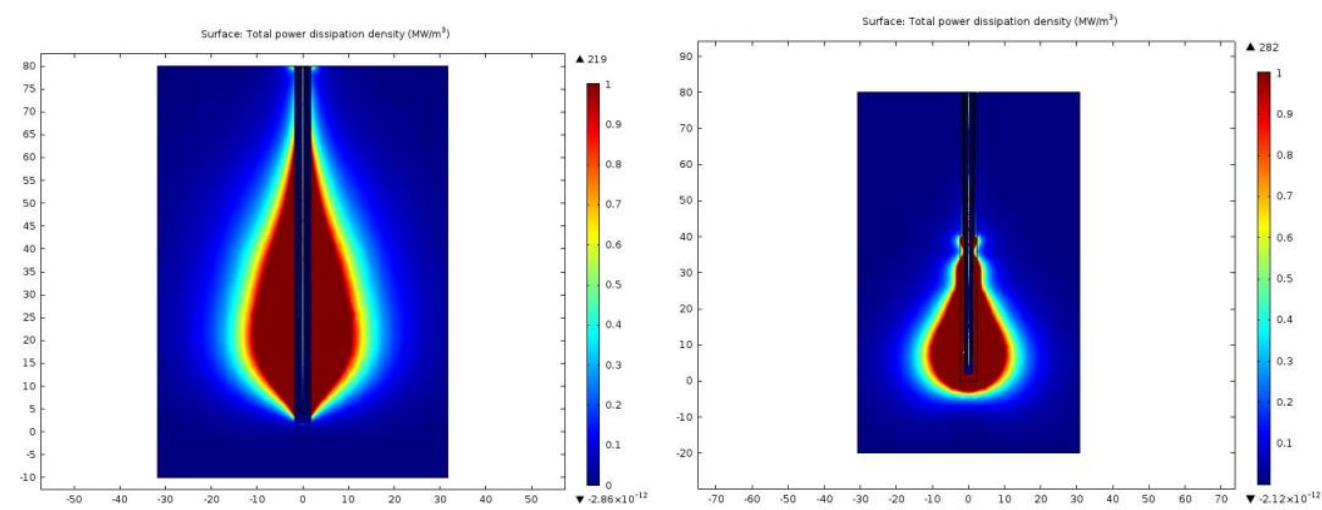

Figure 1 I i and ii 50w for 10mins without water cool and with water cool respectively.
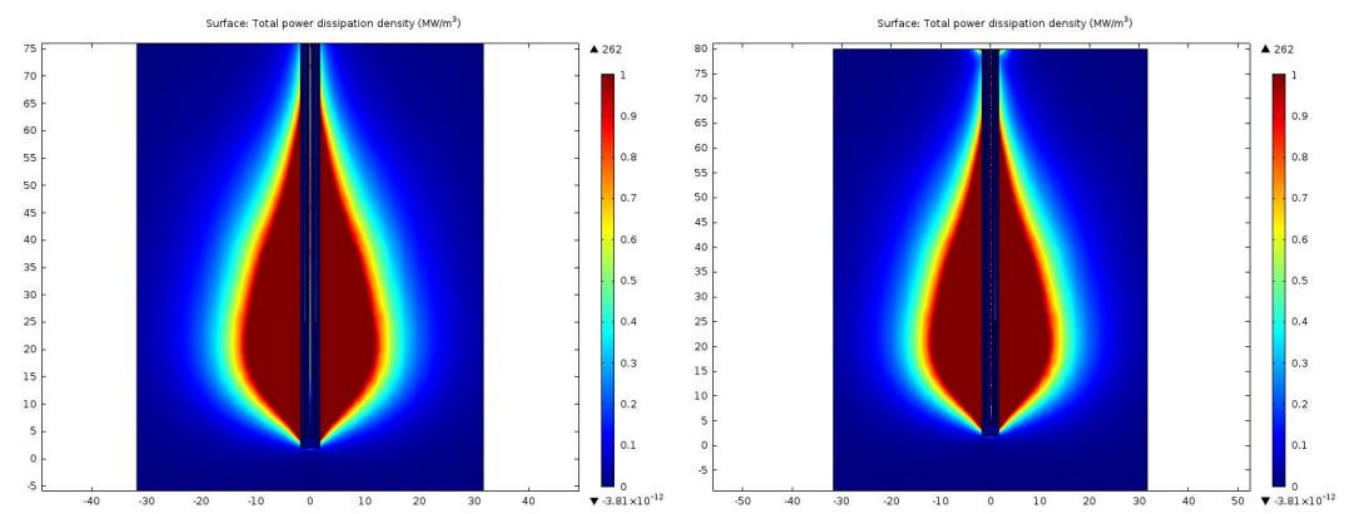

Figure $1 \mathrm{j}$ ii and ii . $60 \mathrm{w}$ for $3 \mathrm{mins}$ without water cool and with water cool respectively.
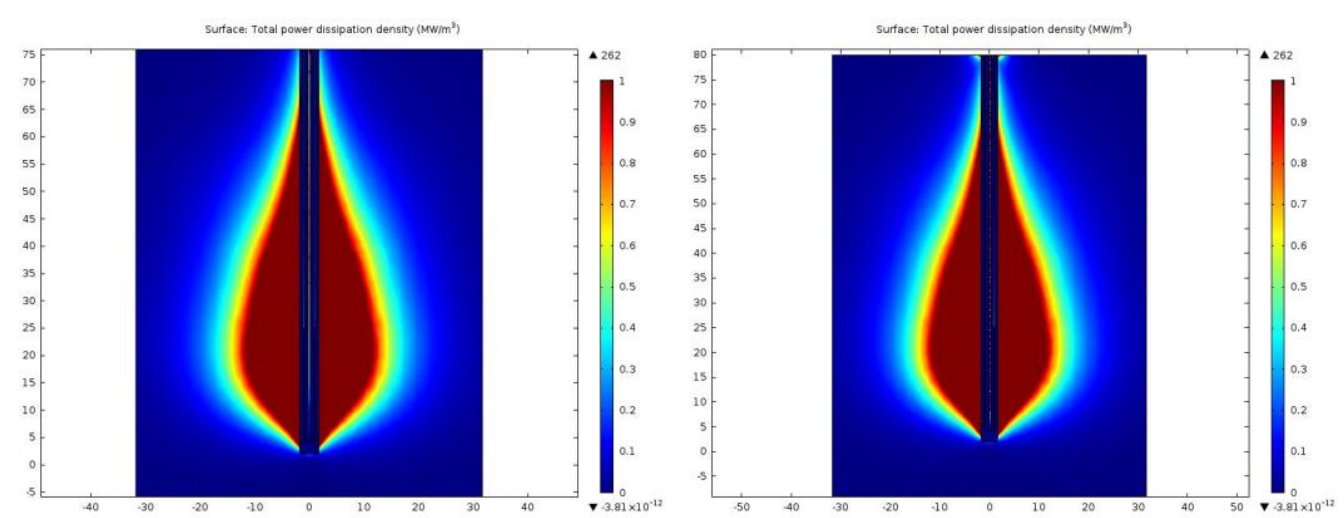

Figure $1 \mathrm{k}$ i and ii $60 \mathrm{w}$ for 5 mins, without water cool and with water cool respectively. 

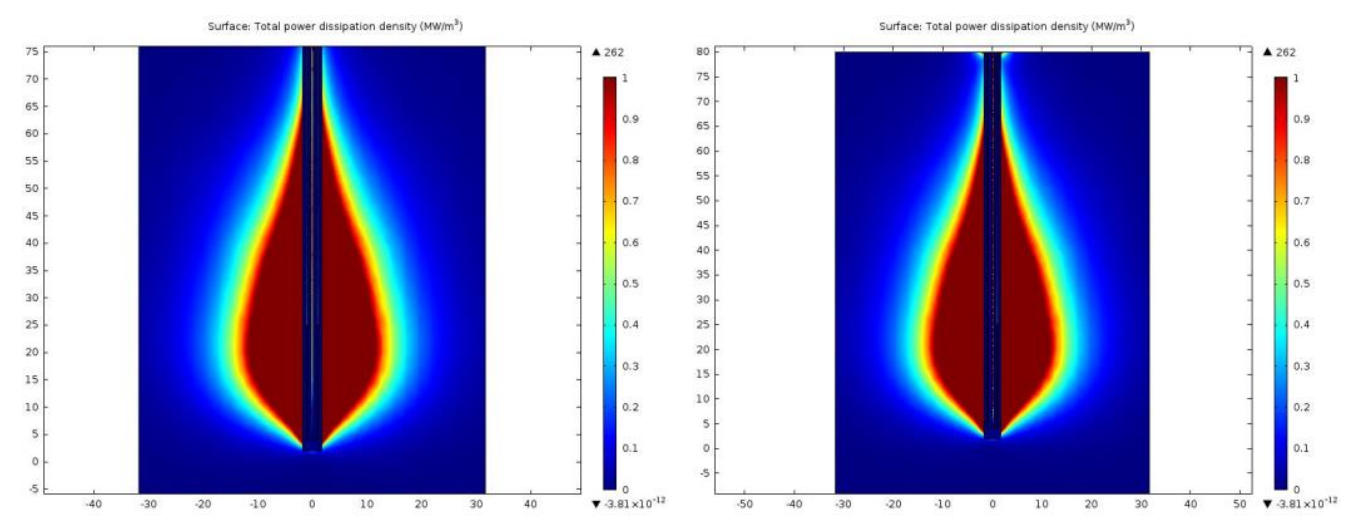

Figure 1L i and ii 60w for 10mins without water cool and with water cool respectively.
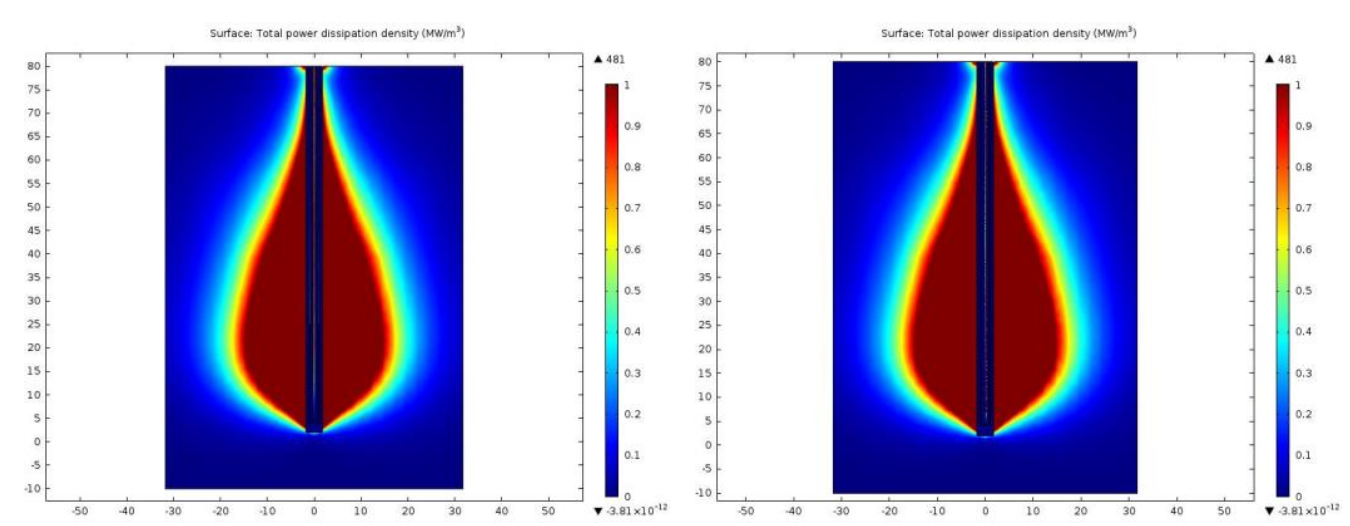

Figure $1 \mathrm{~m}$ i and ii $110 \mathrm{w}$ for 3 mins without water cool and with water cool respectively.
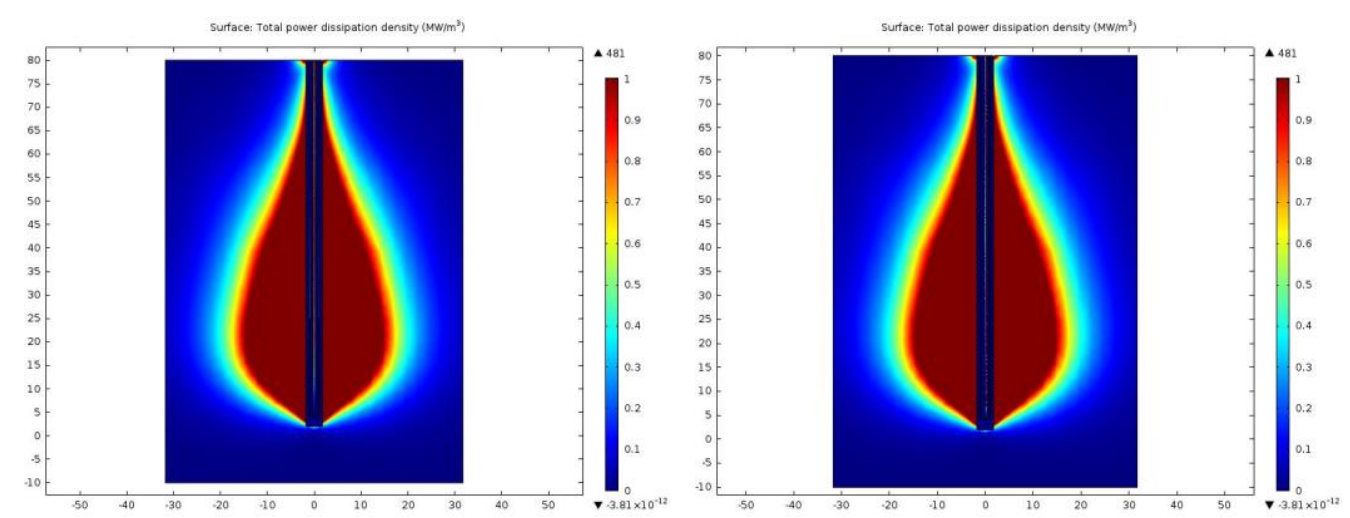

47

To cite this article: Femi AO, Agbasi OE, Emmanuel FO, Etuk SE. (2019). Effect of Water-Cooled Loop Monopole Antenna on Microwave Ablation Efficiency. MAKU J. Health Sci. Inst., 7(2), 41-54. 
Figure $1 \mathrm{n}$ i and ii $110 \mathrm{w}$ for $5 \mathrm{mins}$ without water cool and with water cool respectively.
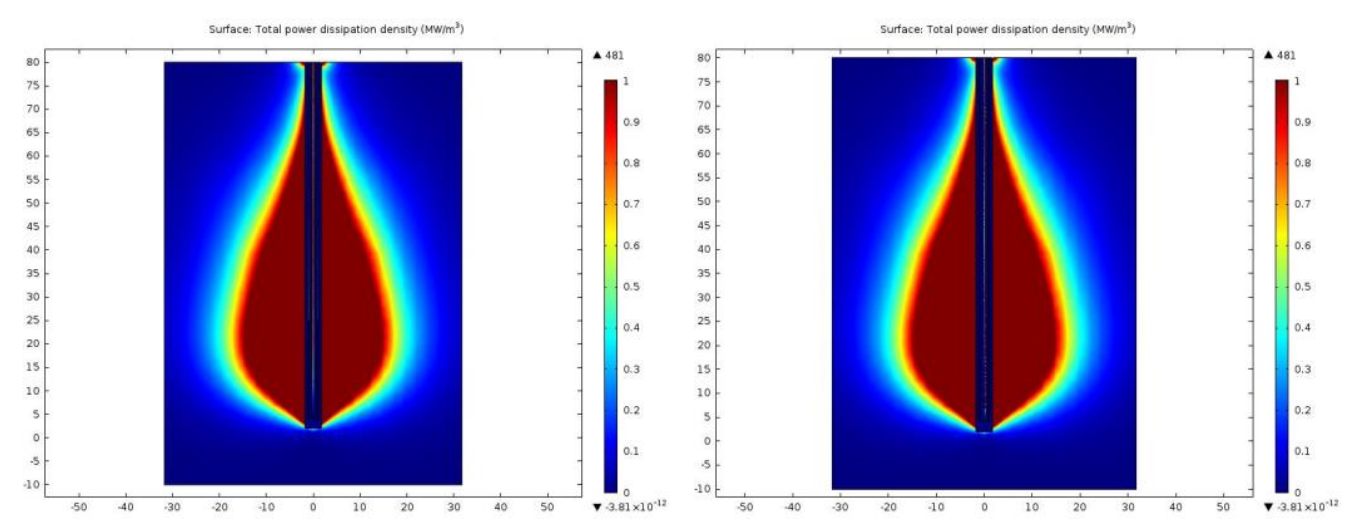

Figure $1 \mathrm{O}$ i and ii 110w for 10mins without water cool and with water cool respectively.
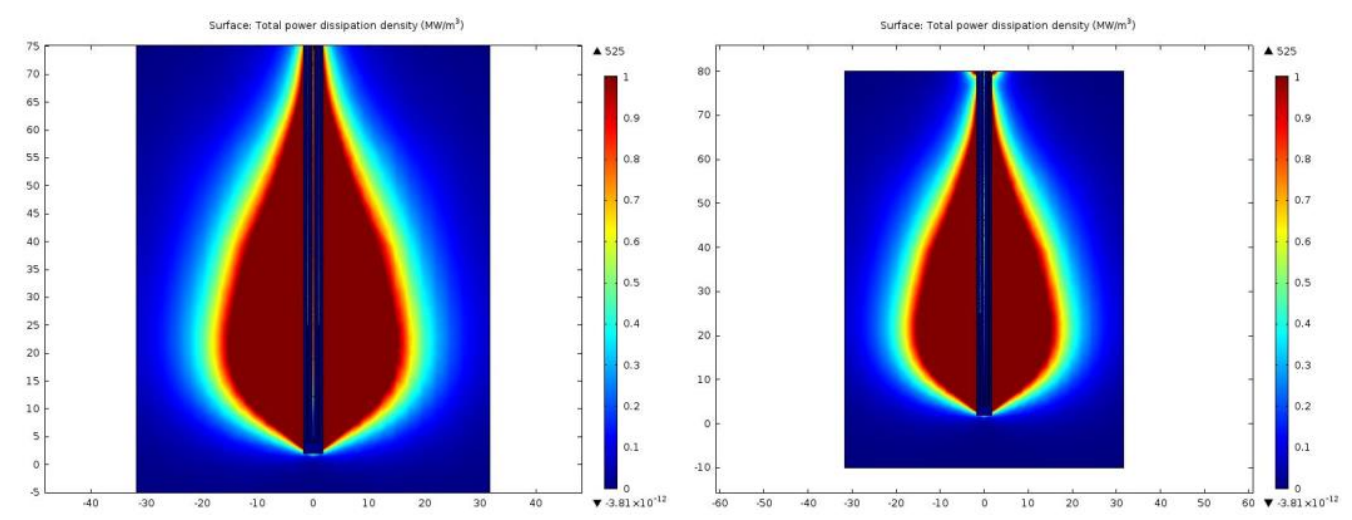

Figure 1P i and ii 120w for 3mins without water cool and with water cool respectively. 

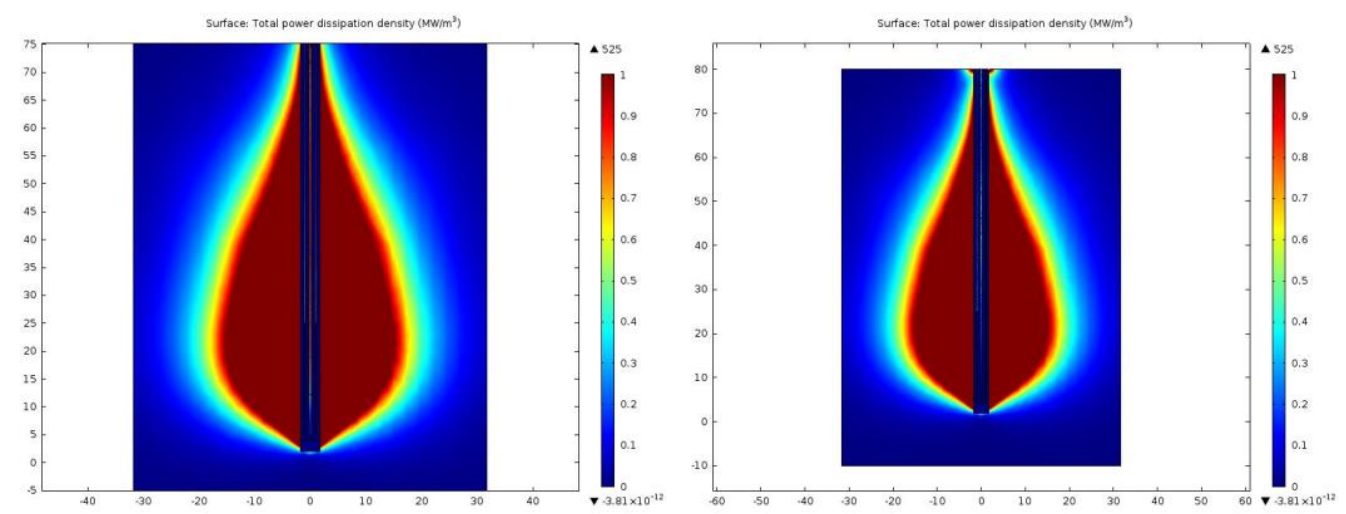

Figure 1Q i and ii 120w for 5mins without water cool and with water cool respectively.
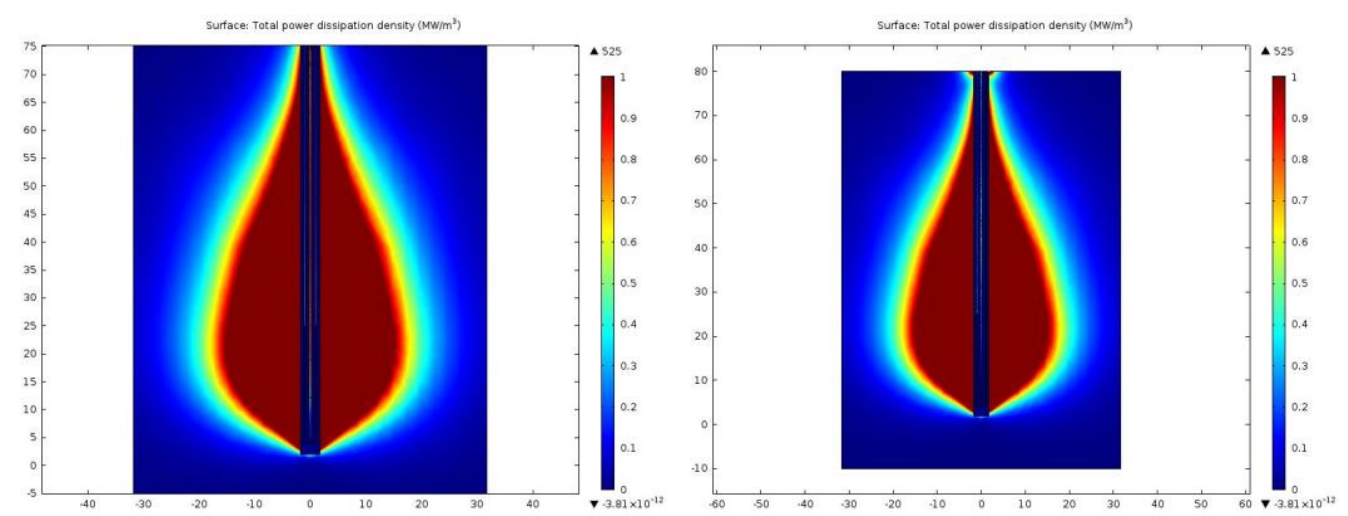

Figure $1 \mathbf{R}$ i and ii 120w for 10mins without water cool and with water cool respectively.

Table 1. Simulation reading of time and diameter of antenna without cooling unit

\begin{tabular}{lllllll}
\hline Time & $\begin{array}{l}\mathbf{D}_{\mathbf{0}} \mathbf{2 0 W} \\
(\mathbf{m m})\end{array}$ & $\begin{array}{l}\mathbf{D}_{\mathbf{0}} \mathbf{3 0 W} \\
(\mathbf{m m})\end{array}$ & $\begin{array}{l}\mathbf{D}_{\mathbf{0}} \mathbf{5 0 W} \\
(\mathbf{m m})\end{array}$ & $\begin{array}{l}\mathbf{D}_{\mathbf{0}} \mathbf{6 0 W} \\
(\mathbf{m m})\end{array}$ & $\begin{array}{l}\mathbf{D}_{\mathbf{0}} \mathbf{1 1 0 W} \\
(\mathbf{m m})\end{array}$ & $\begin{array}{l}\mathbf{D}_{\mathbf{0}} \mathbf{1 2 0} \mathbf{W} \\
(\mathbf{m m})\end{array}$ \\
\hline $\mathbf{6 0}$ & 8.45 & 12.1 & 13.3 & 18.8 & 20.78 & 20.75 \\
$\mathbf{1 2 0}$ & 14.27 & 18.35 & 20.5 & 27.52 & 28.1 & 28.98 \\
$\mathbf{1 8 0}$ & 17.95 & 22.38 & 23.5 & 29.88 & 32.68 & 33.58 \\
$\mathbf{2 4 0}$ & 20.65 & 25.14 & 27.2 & 33.58 & 36 & 37.42 \\
$\mathbf{3 0 0}$ & 23.05 & 28.04 & 28.7 & 36.38 & 36.68 & 41.78 \\
$\mathbf{3 6 0}$ & 24.9 & 29.71 & 31.2 & 38.54 & 40.18 & 42.78 \\
$\mathbf{4 2 0}$ & 26.27 & 31.58 & 31.8 & 40.48 & 42.18 & 43.48 \\
$\mathbf{4 8 0}$ & 27.44 & 32.94 & 33.15 & 42.08 & 42.82 & 44.9 \\
$\mathbf{5 4 0}$ & 28.48 & 33.94 & 34.4 & 43.36 & 44.92 & 46.34 \\
$\mathbf{6 0 0}$ & 29.28 & 34.6 & 34.7 & 44.38 & 46.02 & 46.98 \\
\hline
\end{tabular}




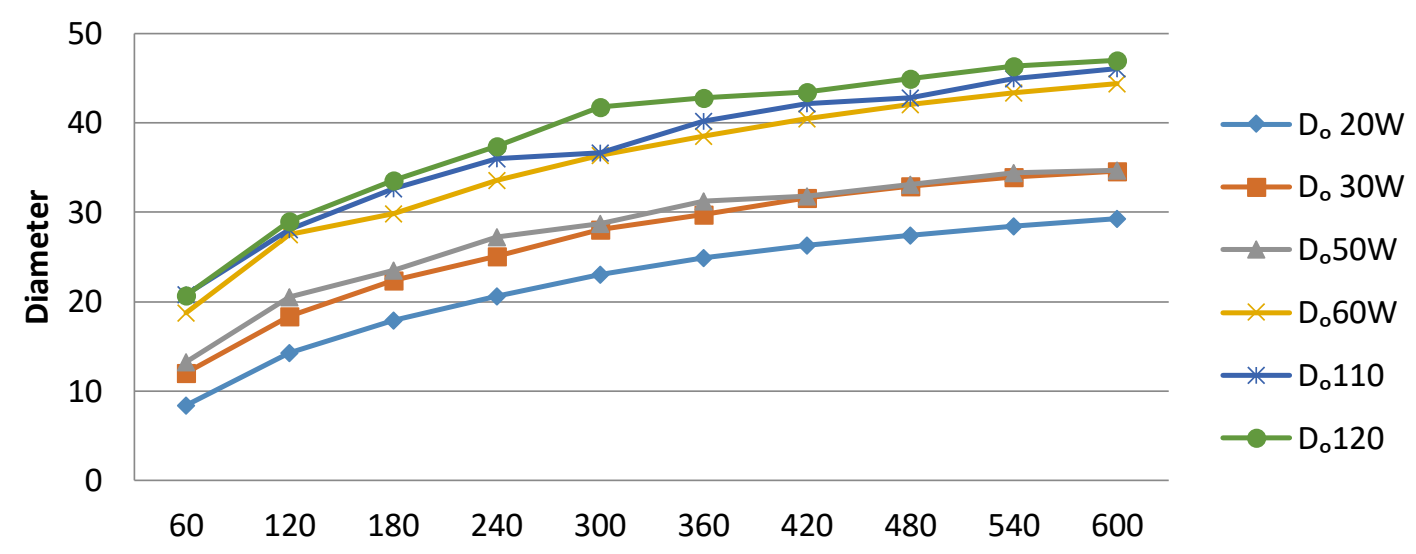

Figure 2. The diameter ( $\mathrm{mm}$ ) against time(s), for simulation without water cooled unit

- The graph shows that ablation diameter increases with time from 60 s to 600 s, with 600 s having the highest diameter.

- It also shows that ablation diameter increases with respect to power from $20 \mathrm{w}$ to $120 \mathrm{w}$, with $120 \mathrm{w}$ having the highest diameter.

All the mean diameters of simulation with water cool antenna were also tabularized, for ablation of $20 \mathrm{~W}$, $30 \mathrm{~W}, 50 \mathrm{~W}, 60 \mathrm{~W}, 110 \mathrm{~W}$ and $120 \mathrm{~W}$ at time $60(\mathrm{~s})-600(\mathrm{~s})$ as shown below.

Table 2. Simulation reading of time and diameter of antenna with water cooled unit

\begin{tabular}{lllllll}
\hline Time & $\begin{array}{l}\mathbf{D}_{\mathbf{0}} \mathbf{2 0} \\
\mathbf{( m m})\end{array}$ & $\begin{array}{l}\mathbf{D}_{\mathbf{0}} \mathbf{3 0 W} \\
(\mathbf{m m})\end{array}$ & $\begin{array}{l}\mathbf{D}_{\mathbf{0}} \mathbf{5 0 W} \\
\mathbf{( m m})\end{array}$ & $\begin{array}{l}\mathbf{D}_{\mathbf{0}} \mathbf{6 0 W} \\
\mathbf{( m m})\end{array}$ & $\begin{array}{l}\mathbf{D}_{\mathbf{0}} \mathbf{1 1 0 W} \\
\mathbf{( m m})\end{array}$ & $\begin{array}{l}\mathbf{D}_{\mathbf{0}} \mathbf{1 2 0} \mathbf{W} \\
\mathbf{( m m})\end{array}$ \\
\hline $\mathbf{6 0}$ & 6.82 & 10.48 & 14.78 & 16.4 & 19.02 & 19.02 \\
$\mathbf{1 2 0}$ & 12.10 & 16.08 & 21.34 & 23.4 & 25.88 & 25.84 \\
$\mathbf{1 8 0}$ & 15.50 & 19.86 & 25.38 & 27.18 & 31.50 & 30.50 \\
$\mathbf{2 4 0}$ & 18.06 & 22.72 & 28.48 & 30.60 & 33.68 & 33.68 \\
$\mathbf{3 0 0}$ & 19.08 & 24.90 & 30.86 & 32.78 & 36 & 36.22 \\
$\mathbf{3 6 0}$ & 21.40 & 26.54 & 32.58 & 34.94 & 36.22 & 38.28 \\
$\mathbf{4 2 0}$ & 22.94 & 27.90 & 34.38 & 36.48 & 40.10 & 40.10 \\
$\mathbf{4 8 0}$ & 24.00 & 29.18 & 35.58 & 37.58 & 41.52 & 41.5 \\
$\mathbf{5 4 0}$ & 24.78 & 30.14 & 36.48 & 38.88 & 42.68 & 42.68 \\
$\mathbf{6 0 0}$ & 25.42 & 30.7814 & 37.28 & 39.9 & 43.16 & 43.6 \\
\hline
\end{tabular}




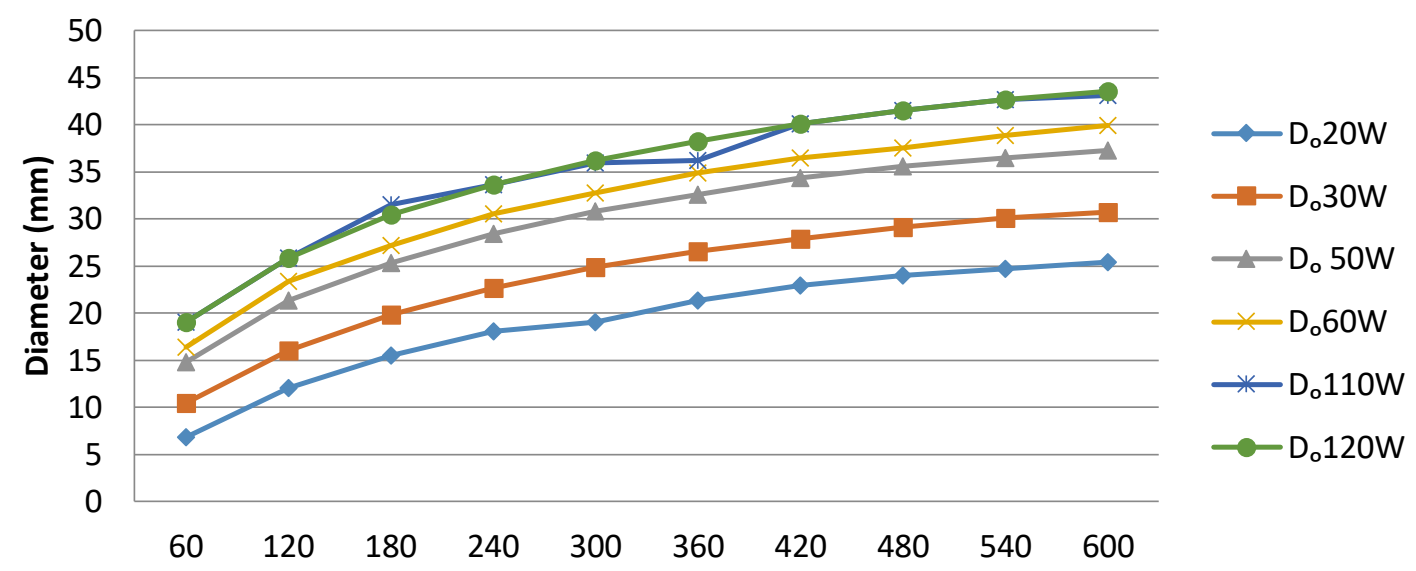

Figure 3. Diameter against time for antenna with water cooled unit

- The graph above shows that as the time increases, the ablation diameter increases, with respect to power from $20-120 \mathrm{~W}$, but the diameter at each power is reduced because of the water cool effect.

- The graph also shows that as the time increases from 60 s to 600 s the ablation diameter increases. increased rapidly with respect to time. Also, the percentage increment in power, from $20 \mathrm{w}-120 \mathrm{w}$, from $60 \mathrm{~s}-20 \mathrm{w}$ to $600 \mathrm{~s}-120 \mathrm{w}$ showed $455.6 \%$, this as well portrayed that diameter increased with increase in power. Similar increment was found in antenna length, considering $20 \mathrm{w}$ at $60 \mathrm{~s}-600 \mathrm{~s}$, the

\section{Discussion}

The study compared the result gotten from using a closed loop water cooled monopole microwave antenna with the same monopole antenna without a water cool system. The difference between the loop microwave antennas used in this study and other thermal ablation arrays (multiple prong RF electrodes) involves the ability to completely encircle a tumor with the loop antennas, which effectively creates a cage in which the tumor is entrapped. This has the advantage of providing precise targeting of a specific area for thermal destruction while minimizing collateral damage (Shock, 2004).

Considering the result for computer simulation with cooling unit, the diameters gotten for $20 \mathrm{w}$ from $60 \mathrm{~s}-600 \mathrm{~s}$ gave a high percentage increase of $246 \%$, this showed that ablation diameter increase gave $119.3 \%$, as the power increased, from $20 \mathrm{w}$ to $120 \mathrm{w}$, there was high increment from $20 \mathrm{w}-60 \mathrm{~s}$ to $120 \mathrm{w}-600 \mathrm{~s}$, the percentage increment value was $199.7 \%$. For the water cool, in the result gotten for 20 watt for $60 \mathrm{~s}-600$ s, there was an increment of $272 \%$ in diameter, the length also showed an increment of $110 \%$. As the power increases from $20 \mathrm{w}$ to $120 \mathrm{w}$ there was an increase of $539 \%$ in length and $194 \%$ in diameter. Using data analysis for the result obtained without water $\mathrm{cool}$, the mean standard deviation gotten for $20 \mathrm{w}$ was $26.88 \pm 6.78$, at $30 \mathrm{w}$ the mean standard deviation was $26.878 \pm 6.78$, at the highest power, $120 \mathrm{w}$ the mean standard deviation was $38.70 \pm 6.78$. It was observed that the standard deviation remains the same (6.78). Also, the result gotten from the water-cooled simulation (4.14), at $20 \mathrm{w}$ from $60 \mathrm{~s}$ to $600 \mathrm{~s}$ the mean standard deviation was $19 \pm 6.05$ and at $30 \mathrm{w}$ the mean standard deviation was $23.86 \pm 6.05$, at the highest power, 
$120 \mathrm{w}$, the mean standard deviation was $35.14 \pm$ 6.05 , showing that the standard deviation remains the same. The reflection coefficient for simulation without water cool was $-17.0882 \mathrm{~dB}$, which was the same for all the powers, water cool simulation also showed the same reflection coefficient ($3.1436 \mathrm{~dB}$ ) for all the powers.

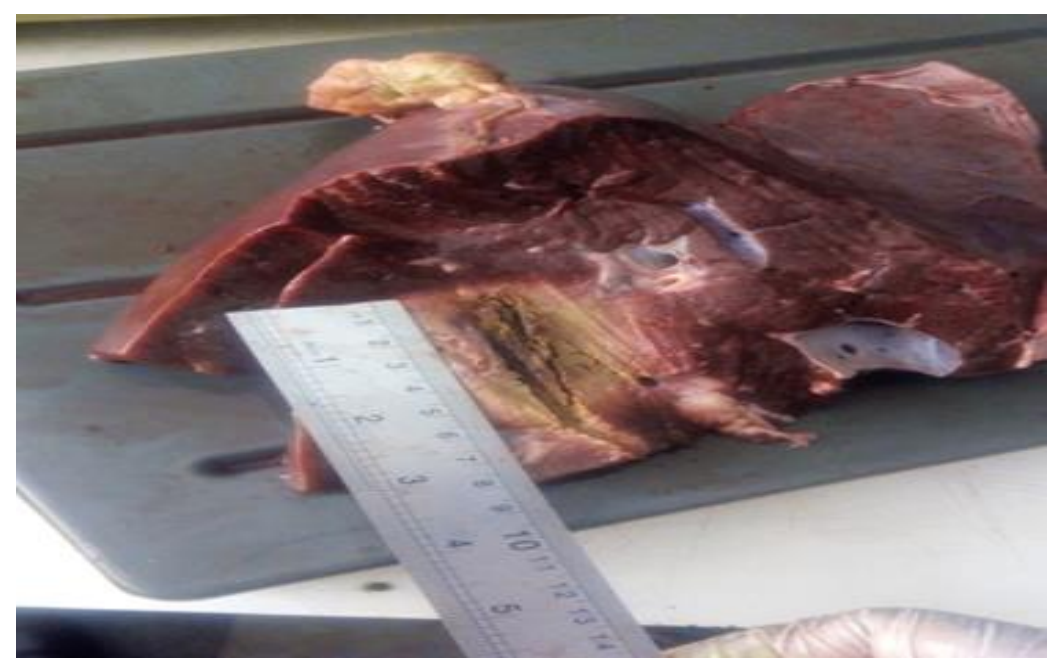

Figure 4. Represents experimental simulation without water cool for $5 \mathrm{mins}$ with $60 \mathrm{~W}$, the length was $5.8 \mathrm{~cm}$, the diameter $5 \mathrm{~cm}$ and the aspect ratio was 0.862 .

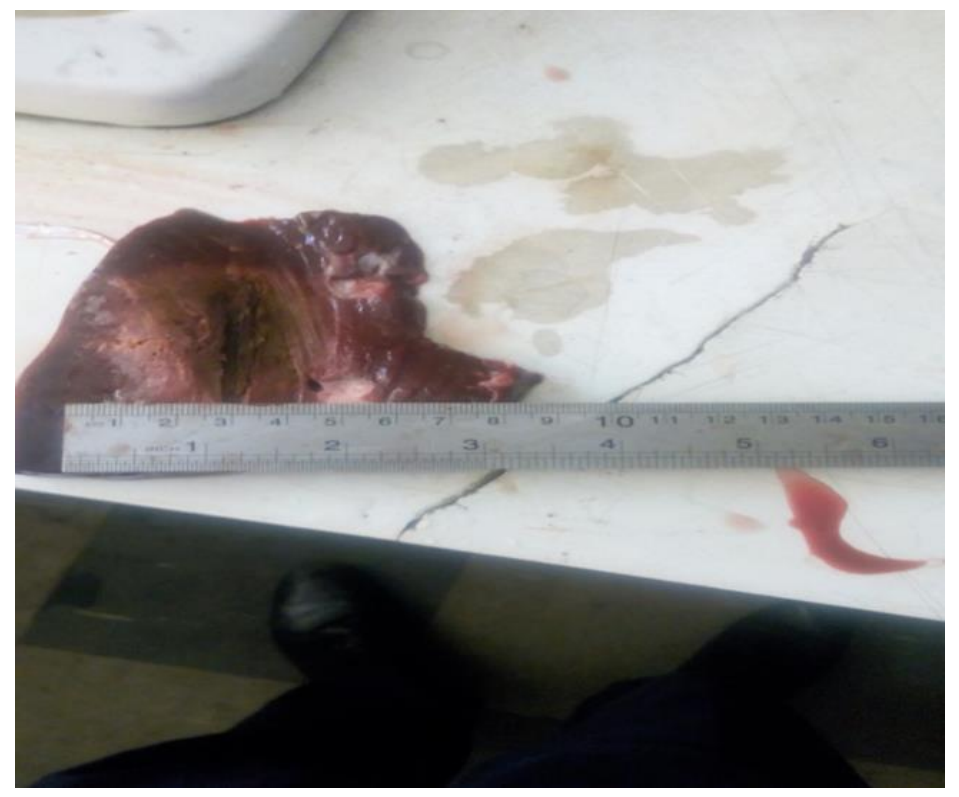

Figure 5. Represents experimental work with water-cool $60 \mathrm{w}$ at $5 \mathrm{mins}$, the diameter was $4.8 \mathrm{~cm}$, the ablated length was 5.5 and the aspect ratio was 0.87 . 
Comparing the two antennas, antenna without water cooling system has increased diameter and length than antenna with water cooling system. Starting with the lowest watt $(20 \mathrm{w})$, at $5 \mathrm{mins}$ the diameter decreased by $-17.2 \%$, the length decreased by $-32.9 \%$ and aspect ratio for the two antennas increased by $23.40 \%$. For medium power $(60 \mathrm{w})$, at $5 \mathrm{mins}$, the diameter decreased by $-9.89 \%$, length decreased by $-37.9 \%$, and aspect ratio decreased by $45.24 \%$. The diameter for highest watt $(120 \mathrm{w})$, at $5 \mathrm{mins}$, showed a percentage decrease of $-13.3 \%$, the lengths for the same watt at the same 5 mins showed a percentage decrease of $-38.2 \%$ and the aspect ratio showed a percentage increase of $40.5 \%$. In the experimental ablation was carried out at $60 \mathrm{w}$ and $120 \mathrm{w}$ for 5 minutes and 10 minutes for antenna without water cool and antenna with water cool respectively (Figure $4-5$ ), the result as well showed that ablation length and diameter increased with time and power. Using paired sample t-test, the P-values gotten from diameters for low power without water cool and water cool for (20W-30W) were, 0.335 and 0.001 respectively, showing no statistically significant change in diameters for water cooled but significant change in diameters with water cool. There was significant change in diameter of medium power, $\mathrm{p}$-value $=$ 0.001 in both cases. In high power, both simulations showed no significant difference in the

diameters. The $\mathrm{p}$ values gotten from length for low power showed no significant difference for simulation without cooling unit $\mathrm{p}=0.040$ but showed significant difference for water cool, $\mathrm{p}=$ 0.001. In medium power, simulation without cooling unit showed significant difference in length, $\mathrm{p}=0.001$, why water cooled showed no showed no significant difference, $\mathrm{p}=0.646$. There was no significant difference in simulation lengths of high power in both water cool and non-water cool.

This study is similar to another work on evaluation of the clinical implementation of triangular and spherical designs for simultaneous multiple- antenna ablation of human hepatocellular carcinoma (HCC) with a recently engineered microwave coagulation system. The diameters gotten during the study were 16.7, 51.7, and $54.3 \mathrm{~cm}$ in $3,5-10$ minute ablation cycle. It was observed that the ablation with the longest time yielded the most uniformly round ablation shape (Yu et al, 2006).

It as well shared the same sentiment with another research on investigation of the result of microwave heating near large vasculature using coupled fluid-flow and thermal analysis, it was observed that low-flow conditions could cause cytotoxic heating and, therefore, vessel thrombosis and endothelial damage of downstream tissues. This is similar to this study, the effect of water cool antenna was shown in Figure 1, it was observed tissue without water cool could produce high ablation length and diameter, resulting to backward heating, hence, causing endothelial damage (Chiang et al., 2012). Such conditions might be more prevalent in patient with severe cirrhosis or compromised blood flow. High-flow conditions create the more familiar heat-sink effect that could protect perivascular tissues from the intended thermal damage.

\section{References}

Açıkgöz, H., Türer. İ., 2014. A Novel Microwave Coaxial Slot Antenna for Liver Tumor Ablation. Advanced Electromagnetics, 2014; 3(1): 20-15.

Bertram, J.M., Yang, D., Converse, M.C., Webster, J.G., Mahvi, D.M., 2006. A Review of Coaxial-Based Interstitial Antennas for Hepatic Microwave Ablation. Critical Reviews in Biomedical Engineering 2006; 34(3):187-213.

Chiang, J., Hynes, K., Brace. CL., 2012. FlowDependent Vascular Heat Transfer during Microwave Thermal Ablation. Conf Proc IEEE Eng Med Biol Soc. 2012 August; 2012: 5582-5585. doi:10.1109/EMBC.2012.6347259. 
Hinshaw, J.L., Lubner, M.G., Ziemlewicz, T.J., Lee, F.T., Jr, Brace, C.L., 2014. Percutaneous tumor ablation tools: Microwave, radiofrequency, or cryoablation-What should you use and why? 2014; 35:1344-1362 Doi: 10.1148/rg.345140054.

Kaur, S., Maini, S., 2007. Ablation Options for Treatment of HCC - MWA and RFA. International Journal of Emerging Technologies in Computational and Applied Sciences (IJETCAS) 2279-0047; 2007:2279-0055.

Lin. J.C., Wang, Y.J.; 1996. "The cap-choke catheter antenna for microwave ablation treatment" IEEE Trans Biomed Eng. 1996;43(6):657-60.

Shock, S.A., Meredith, K., Warner, T.F., Sampson, L.A., Wright, A.S., Winter III, T.C.,
Mahvi, D.M., Fine, J.P., Lee, F.T., 2004. Microwave Ablation with Loop Antenna: In Vivo Porcine Liver Model. Radiology 2004; 231:143149. Doi: 10.1148/radiol.2311021342.

Simon, C.J., Dupuy, D.E., Mayo-Smith, W.W., 2005. Microwave Ablation: Principles and Applications. Radio Graphics 2005; 25: S69-S83. Doi: $10.1148 /$ rg.25si055501.

Yu, N.C., Lu, D.S.K., Raman, S.S., Dupuy, D.E., Simon, C.J., Lassman, C., Iaswad, B., Ianniti, D., Busuttil. R.W., 2006. Hepatocellular Carcinoma: microwave ablation with multiple straight and loop antenna clusters pilot comparison with pathologic findings. Radiology 2006; 239:269-275. Doi: 10.1148/radiol.2383041592 